\title{
A cobertura de cidades devastadas em testemunhos paralisantes e interpretativos de correspondentes internacionais no projeto Memória Globo
}

\author{
The coverage of devastated cities in paralyzed and interpretative testimonies of \\ international correspondents in the Globo Memoir Project.
}

Simão Farias Almeida - Universidade Federal de Roraima I Boa Vista I RR I Brasil I simonjp@hotmail.com https://orcid.org/0000-0001-8582-7485

Resumo: As representações da cidade no discurso midiático fogem dos sentidos funcionalistas e racionalistas, legitimando a fragmentação das experiências de sujeitos no construto de narrativas sobre os lugares a partir dos quais falam, conforme Martín-Barbero (2004). Seguindo o método de pragmática do discurso jornalístico, na esteira de Rodrigues (2001) defenderemos que os relatos dos correspondentes internacionais são ininterruptos, não hierárquicos, podendo aparecer fora das produções jornalísticas e combinatórios de perspectivas políticas, econômicas, sociais e ambientais. Neste sentido, analisaremos testemunhos de repórteres no projeto Memória Globo (2018) a respeito de coberturas de catástrofes ambientais, demonstrando que o jornalismo interpretativo contraria a mera apresentação de consequências dos fatos e permite 0 apontamento de soluções à comunidade nacional de origem dos correspondentes, necessárias ao restabelecimento de cidades devastadas.

Palavras-chave: Cidades devastadas. Correspondentes internacionais. Cobertura ambiental interpretativa.

Abstract: Representations of the city in media discourse escape the functionalist and rationalist senses, thereby legitimizing the fragmentation of the experiences of subjects in constructing narratives regarding the places from which they speak, according to Martín-Barbero (2004). Following the pragmatic method of journalistic discourse, in the wake of Rodrigues (2001), we will argue that reports from international correspondents are uninterrupted, non-hierarchical and may take place outside journalistic productions, combining political, economic, social and environmental perspectives. In this sense, we set out to analyse the testimonies of reporters in the Globo Memoir Project (2018) regarding the coverage of environmental disasters, demonstrating that interpretive journalism is contrary to the mere presentation of consequences, and enables correspondents to point out to their original national community solutions that are necessary for re-establishing devastated cities.

Keywords: Devastated cities. International correspondents. Interpretative environmental coverage.

http://dx.doi.org/10.22484/2318-5694.2019v7n14p31-51

Recebido em outubro 2018- Aprovado em fevereiro 2019 


\section{Introdução}

A cidade moderna, segundo Marshall Berman (1986), é carregada de fantasmagorias de vitrines e avenidas em meio às arquiteturas destruidoras de cartografias e sociabilidades individuais e coletivas. Ela constrói suas narrativas através das "ruínas" cotidianas de casas, prédios e moradores. Os testemunhos de vítimas dos problemas sociais, políticos, econômicos e ambientais as transformam em sujeitos da e na cidade capazes de denunciar as crises e interferir nas dinâmicas urbanas. 0 jornalismo contribui com esses construtos discursivos ao instaurar na modernidade a capacidade do jornalista de observar os fatos nas ruas, não somente de escrever sobre eles dentro das redações, rotina restrita de opinião à distância da realidade e comum aos profissionais, geralmente escritores, até o século XIX.

As representações da cidade nas pesquisas de comunicação e jornalismo devem considerar os aspectos objetivos dos fatos e as perspectivas subjetivas das fontes informativas. Jesús Martín-Barbero (2004, p. 277) critica os funcionalismos arquitetônicos e as estéticas racionalistas por meio dos quais a cidade é um sistema fechado, legitimando-a ao contrário pelas "figuras que demarcam as ruas e praças" e "fissuras que introduz [sic] a desordem das experiências e dos relatos". O espaço urbano, desta forma, deve ser entendido tanto em sua fisiologia quanto nas formas de experimentar a pertinência ao território e de viver as identidades. Ele, então, se constitui por sua vida cotidiana e os traçados construídos pelos sujeitos passantes e narradores das vivências. A mídia colabora nesta perspectiva ao compreender cada lugar como uma narrativa formada de tramas sociais.

O jornalista testemunha se posiciona a respeito dos acontecimentos do espaço citadino enquanto morador e profissional. Seus discursos são mediadores do olhar e das impressões da paisagem observada. Segundo 
Adriano Duarte Rodrigues (2002, p. 217-218), o discurso midiático flui de maneira constante e ininterrupta, dá credibilidade à narração dos fatos independente do lugar de fala do enunciador. Apesar de o teórico atribuir esses aspectos ao "uso predominante da terceira pessoa", ou seja, dos entrevistados nas narrativas jornalísticas, ele também aponta que seus discursos escondem os processos de gestação. Acreditamos ser possível confrontar a assertiva sobre essa lacuna por parte dos propósitos editoriais das redações e legitimar os enunciados do jornalista reveladores da cobertura e das decisões ideológicas dos meios de comunicação. Além das fontes oficiais e não oficiais, o repórter também fala nessas narrativas e inclusive fora delas. Utilizaremos os pressupostos metodológicos em pragmática do discurso midiático de Adriano Duarte Rodrigues (2001), com 0 intuito de analisar os testemunhos de correspondentes internacionais da Rede Globo acerca de suas coberturas de cidades arrasadas por catástrofes ambientais ou impactantes ao meio ambiente.

Rodrigues (2001, p. 19) valoriza o saber que se processa "por transferência, redução e deslocamento dos discursos constituídos e obrigados pelas determinações da ordem dominante". Seguindo esta premissa, compreenderemos a expansão do construto discursivo dos jornalistas nas matérias televisivas ao conjunto de testemunhos organizado pelo projeto Memória Globo. Ele permite a percepção, anos após as reportagens, das experiências dos repórteres durante a cobertura das cidades destruídas por problemas ecológicos, climáticos e humanos. Em segundo lugar, o método reconhece as perspectivas ou os pontos de vista a partir dos quais se fundam os discursos. Eles "passam a equivalerse, se os considerarmos como lances estratégicos de legitimação. Já não podemos, por conseguinte, hierarquizá-los em torno de uma perspectiva dominante sem incorrermos no risco de aceitar como indiscutível a sua dominação" (RODRIGUES, 2001, p. 19). Desta forma, analisar os discursos fora das matérias televisivas não deixa de ser uma pesquisa em 
jornalismo e, além disso, não minimiza os testemunhos do projeto das Organizações Globo em relação àqueles presentes nos relatos dos jornalistas durante a transmissão dos fatos por meio das reportagens. Recortaremos as percepções deles a respeito das cidades devastadas por fatos ambientais.

Por fim, Rodrigues (2001, p. 20) destaca a natureza serial e transitiva da combinatória dos discursos: "é transitiva, na medida em que a posição do próprio sujeito é reflexo de uma palavra outra que o constitui como instância legítima de enunciação". A partir disso, poderemos comparar os construtos discursivos dos diferentes correspondentes internacionais mesmo eles cobrindo acontecimentos em países e situações diferentes. Se os discursos midiáticos na pesquisa acadêmica e científica são considerados ininterruptos, não hierárquicos, apesar de eles serem nas produções jornalísticas, e confrontáveis entre si, analisaremos os depoimentos do projeto Memória Globo (2018) sem prejuízo das matérias televisivas dos correspondentes, referenciadas quando for necessário.

\section{Testemunho do correspondente internacional}

O testemunho foi uma experiência típica do jornalismo moderno emergente entre as metades dos séculos XIX e XX. Géraldine Muhlmann (2008, p. 23;29) distingue o posicionamento de dois tipos de jornalista na época quando eles eram convocados a cobrir fatos no próprio país ou em outro país ou continente, caso dos correspondentes de guerra enviados para testemunhar os combates armados. O jornalista unificador surgiu durante a transição do jornalismo de opinião à reportagem, portanto, da descentralização da figura do comentarista detentor do discurso, daí o jornalista moderno ter que forjar o papel de mediador dos fatos e não mais meramente de proprietário de ideias. A autora enumera as novas 


\section{tríade}

perspectivas jornalísticas pertinentes a essa transição: o polemista (MUHLMANN, 2008, p. 17) e a testemunha (p. 23), através de uma espécie de procuração feita pelos leitores, passam a descrever fatos em comum a uma coletividade. Não distante deste contexto de confluência de categorias jornalísticas opinativas e informativas, o jornalista descentralizador, correspondente internacional, não se considera fazendo parte de uma comunidade estrangeira e representando-a; ele só testemunha o fato porque se deslocou da coletividade à qual pertence (MUHLMANN, 2008, p. 29).

Géraldine Muhlmann (2008, p. 23) defende o surgimento da experiência do testemunho devido à separação entre a opinião e a sensação, entre os olhos que observam e a voz que expressa, transformando o jornalista numa espécie de "embaixador", mediador de sua comunidade ao representá-la no ato de testemunhar os fatos. Esta mudança no início da modernidade industrial conferiu ao repórter a nova perspectiva discursiva do "eu vi", diante da qual o jornalismo procurou convencionar a mediação no presente, forjando o prolongamento da observação, conferindo ao leitor a possibilidade de simular o sentido de também "estar lá" juntamente com o jornalista. Segundo as assertivas de Muhlmann (p. 23), a preponderância do aspecto factual sobre o opinativo, do olhar em detrimento do pensamento, passava pelo paradoxo do jornalista ao falar de uma experiência própria a si e à coletividade, legitimando o testemunho individual do profissional de redação e social da cidade onde os fatos ocorreram. Nos termos de Jesús Martin-Barbero (2004), o espaço urbano é fragmentário em suas experiências e seus relatos. Neste sentido, o jornalista descentralizador ou correspondente internacional media os testemunhos seus e de outros sujeitos acerca de acontecimentos no exterior à comunidade de seu país. 


\section{tríade}

Conforme aponta Luciane Fassarella Agnez (2017, p. 208-216 ${ }^{1}$ ), o correspondente conhece a cultura, as características históricas e socioeconômicas do país onde se encontra e produz material jornalístico regularmente, independente de episódios factuais.

A editoria internacional, por sua vez, não é considerada jornalismo especializado, porque se dedica a todas as editorias, em âmbito internacional. Mas por essa abrangência toda é que o correspondente deve ser especializado em tudo, saber lidar com vários tipos de matérias" (BRITO, 2004 apud AGNEZ, 2017, p. 1038-1044).

Deste modo, a cobertura jornalística do correspondente faz uso da reportagem factual ou contextual, da convergência editorialística e suas angulações políticas, econômicas, cotidianas, ambientais.

O jornalista Timothy Ash aponta três características essenciais do trabalho dos correspondentes internacionais: "testemunhar (ver e acompanhar, de modo independente, eventos, pessoas e circunstâncias), decifrar (contextualizar e explicar os fatos) e interpretar (o que o fato representa, num quadro comparativo e histórico mais amplo)" (ASH, 2010 apud AGNEZ, 2017, p. 1658-1665). Trata-se de uma opção pela reportagem informativa e interpretativa reveladora dos aspectos plurais e aprofundados do acontecimento e da sociedade onde ele ocorreu.

Nos anos 1970, o crítico brasileiro Luiz Beltrão (1976, p. 42-46) já distinguia o jornalismo interpretativo dos demais. Ele aponta que essa categoria jornalística opera à base da investigação e da informação da atualidade; ao interpretar, busca a ligação dos fatos e explica sua ocorrência; ao investigar, enumera suas causas e origens. No entanto, a interpretação vira opinião se o jornalista tomar posição diante dos dados, contextos, situações. O paradoxo construído a partir desses propósitos é o seguinte: a categoria propõe-se a aprofundar os ligamentos entre os

\footnotetext{
${ }^{1}$ O número de páginas indicado do livro digital de Luciane Fassarella Agnez leva em consideração que a numeração de e-books baixados por meio da plataforma kindle é diferente do livro impresso ou em PDF.
} 


\section{tríade}

elementos da realidade e forja fazê-lo ao burlar o tratamento dos fatos recentes de forma não superficial mesmo o quadro de suas características não tendo forma definida quiçá definitiva.

Todavia, quando o jornalista está diante de uma cobertura ambiental, ele pode se esquivar de cumprir alguns propósitos do jornalismo interpretativo. Ele, principalmente, pode tomar partido pela natureza em detrimento das ações humanas destrutivas. Esta atitude envolve funções do jornalismo ambiental apontadas por Wilson Bueno (2008, p. 165): política de engajamento ecológico e pedagógica de educar o público em favor da preservação.

Partindo das discussões críticas de Beltrão (1976) e Bueno (2008), compreendemos as diferenças das representações da cidade na cobertura informativa e interpretativa, factual e contextual, ambiental e de outras editorias. Podemos dizer que ela é apresentada através de um construto discursivo no qual estão incluídos o testemunho contextual e explicativo, o aprofundamento da ligação dos fatos, as relações entre suas causas e consequências. A cidade interpretada por um correspondente internacional vai ser traduzida à comunidade nacional do país dele por meio de uma pluralidade editorial e suas distintas angulações. A cidade interpretada ambientalmente está sob as escolhas desses aspectos, o engajamento dos sujeitos e a pedagogia ecológica dos repórteres. Seguiremos esta linha de raciocínio ao analisarmos as representações das cidades arrasadas nos testemunhos dos correspondentes internacionais no projeto Memória Globo.

\section{Testemunhos das cidades arrasadas por catástrofes ambientais e humanas}


Correspondentes: bastidores, histórias e aventuras de jornalistas brasileiros pelo mundo é um livro editado pelo projeto Memória Globo, contendo depoimentos de vinte correspondentes que trabalharam em onze países, registrados em 89 entrevistas de áudio ou vídeo, somando quase duzentas horas de gravação (MEMÓRIA GLOBO, 2018, p. 13). Os jornalistas participantes relatam as impressões pessoais e dos personagens das reportagens sobre acontecimentos políticos, diplomáticos, econômicos, religiosos e sociais de repercussão mundial, a exemplo dos atentados de 11 de setembro de 2001 em Nova York, da queda do Muro de Berlim e do tsunami na Tailândia. Conforme aponta o Diretor-Geral de Jornalismo Ali Kamel, por meio dos relatos, os correspondentes internacionais "reencontraram sua história pessoal e souberam contá-la e traduzir, agora em livro, a emoção, a grandeza e os bastidores de todos esses acontecimentos que, anos antes, levaram aos espectadores brasileiros na forma de reportagem de televisão" (MEMÓRIA GLOBO, 2018, p. 11). Eles são apresentados como testemunhas brasileiras de fatos estrangeiros, mediação análoga ao papel de embaixador do jornalista descentralizador apontado por Géraldine MuhImann (2008). Selecionamos depoimentos relacionados a coberturas de desastres ambientais e climáticos com impactos em cidades americana, europeia e asiática.

Luís Fernando Silva Pinto é correspondente da Rede Globo há mais de quarenta anos. Foi enviado especial na Argentina, Nicarágua, em El Salvador, no Reino Unido, na Índia e no Oriente Médio, e estabeleceu-se em Washington por mais de vinte anos para tratar a política estadunidense. Ele cobriu as consequências do Furacão Katrina em Nova Orleans nos Estados Unidos em 29 de agosto de 2005 (MEMÓRIA GLOBO, 2018 , p. 89-90). A região metropolitana da cidade foi a mais atingida pelo rompimento de diques que represavam as águas do lago Pontchartrain, 
inundando as ruas e desabrigando um milhão de pessoas. O repórter relatou os impactos da passagem do furacão na comunidade socialmente mais vulnerável:

Então nos demos conta de que tínhamos que entrar lá, porque era uma situação de abandono da população, uma tragédia humana que uma geração inteira de norteamericanos nunca tinha presenciado. Uma grande cidade do país ao deus-dará. As pessoas estavam completamente entregues. Nova Orleans era uma cidade problemática, onde sempre houve a difícil convivência do ter e do não ter. $E$ nós, ao mesmo tempo em que trabalhávamos, íamos aprendendo 0 que realmente estava acontecendo (MEMÓRIA GLOBO, 2018, p. 108).

O discurso revela o contexto político, econômico, social e ambiental com o qual a equipe de reportagem se deparou: a cidade já tinha problemas devido à má distribuição de renda e foi ainda mais afetada pelo lastro de destruição do furacão Katrina, cuja dimensão ultrapassa os efeitos sociais de tragédias anteriores nos Estados Unidos. Luís Fernando destaca a capacidade dos repórteres em transmitir as informações a partir do reconhecimento dos elementos contextuais. O testemunho emerge os sentidos de uma cidade repartida diante de uma ordem social fragmentária e da catástrofe ambiental. Ele segue endossando a representação do desgoverno, cuja improbidade administrativa acentua as consequências da passagem do furacão:

$E$, no meio de uma avenida, havia milhares de pessoas em condições degradantes. Parecia uma zona de refugiados de país de terceiro mundo. Um descaso das autoridades da Lousiana, porque, no caminho, havíamos passado por uma coluna de mais de 150 ônibus escolares, todos funcionando, cheios de diesel, com rádios. Estavam vazios e a menos de trinta quilômetros de distância. Poderiam resgatar aquelas pessoas. A falta de coordenação em uma hora crítica é o inimigo, e vimos que a organização nos Estados Unidos não é absoluta. O próprio presidente George W. Bush foi muito criticado: ele sobrevoou a região, mas não pousou, por exemplo. A situação era constrangedora para o governo e, 
ao mesmo tempo, perigosa para a população. Nova Orleans estava embaixo de uma água que se tornava mais imunda a cada dia, e os casos de doenças estavam se multiplicando (MEMÓRIA GLOBO, 2018, p. 109).

Trata-se da contextualização de uma cidade paralisada, comparada ao terceiro mundo, pois os ônibus escolares, única rota de evacuação, não estavam disponíveis para retirar moradores vulneráveis de Nova Orleans. O governo federal apresentava-se inerte à grave situação e a comunidade vítima do descaso público presenciava o agravamento da crise ambiental e social na precarização do estado do alagamento e na proliferação de doenças. Através desses depoimentos do repórter, notamos a preocupação de contextualizar os efeitos sociais do desastre, mas não apontar as causas climáticas e políticas da dimensão destrutiva do furacão Katrina. Diante disso, a cidade contextualizada não oferece o mesmo panorama jornalístico que a cidade interpretada, porque a contextualização pode apontar apenas as consequências dos fatos, caso do relato de Luís Fernando Silva Pinto. Sua reportagem televisiva disponibilizada pelo projeto Memória Globo em hotsite acessado por meio de $Q R$ Code disponível no livro também não enumera as causas. Esta denúncia poderia ter sido feita em reportagem anterior, inclusive por outro jornalista. No entanto a recorrência discursiva reforçaria as ações a serem evitadas pelos poderes públicos.

Outro correspondente entrevistado é Marcos Uchoa. Foi escalado desde os anos 1980 para cobrir competições esportivas internacionais, os Jogos Olímpicos de Los Angeles e, dois anos depois, a Copa do Mundo no México em 1986, e as Olimpíadas de Seul no ano de 1988. No escritório de Londres, durante mais de dez anos, testemunhou o tsunami na Ásia, o fim da Guerra da Bósnia, o lançamento do foguete com o astronauta brasileiro Marcos Pontes, a Guerra do Iraque e do Afeganistão (MEMÓRIA GLOBO, 2018, p. 351-352). Dois desastres ambientais aparecem no testemunho dele do projeto Correspondentes: tsunami e terremoto. 0 
tsunami na Ásia em 2004 devastou a costa de oito países no oceano Índico, incluindo a região Phuket no sul da Tailândia, deixando cerca de 250 mil mortos.

Primeiro fomos a uma vila de pescadores, não queríamos mostrar simplesmente os turistas, mas também as pessoas locais, os mais pobres. Nessa comunidade de pescadores, havia um braço de mar que entrava como se fosse um rio, e as embarcações foram jogadas longe. Eram barcos pesqueiros, grandes, arremessados terra adentro. E as pessoas tentavam recuperá-los. Não estamos falando somente das mortes: as pessoas têm que sobreviver, têm que trabalhar. A perda desses barcos significa uma miséria total para elas. Os barcos estavam empilhados, uns em cima dos outros (MEMÓRIA GLOBO, 2018, p. 364).

O depoimento permeado de aspectos socioeconômicos, apesar de não apontar causas, contextualiza os efeitos do tsunami do ponto de vista dos sujeitos socialmente vulneráveis, principalmente daqueles cuja subsistência depende do mar afetado pela dimensão da catástrofe. As fontes consultadas incluíram turistas e moradores pobres, ou seja, ele retratou os impactos em sujeitos de diferentes perfis sociais e econômicos. Em outro país, a cobertura privilegiou um fato de grande repercussão ambiental:

No Sri Lanka, gravamos uma reportagem que, dias depois, a CNN também fez, com um trem que foi arremessado longe. O comboio, que estava lotado de gente que ia para a praia curtir o fim de semana, passava a quinhentos metros da praia. Havia 1,5 mil passageiros, aproximadamente, quando, na verdade, a lotação máxima era de quinhentos. Três pessoas sobreviveram: uma criancinha e dois adultos. Ninguém conseguia entender como o mar podia ser tão forte e jogar um trem longe. Cada vagão estava num lugar, muitos foram parar no meio da selva, que teve as árvores todas destruídas. Os corpos se espalharam (MEMÓRIA GLOBO, 2018, p. 366). 


\section{tríade}

O testemunho apresenta o contexto por meio de dados de vítimas atingidas e sobreviventes, além de enumerar os efeitos na rede ferroviária e na floresta. A representação da cidade arrasada também aparece no relato a respeito das consequências em Banda Aceh na Indonésia:

[...] sem luz, sem água, sem comida, sem nada. Foi tão chocante quanto aquela cena dos corpos. O mar entrou quilômetros adentro, devastando tudo com muita força. Pouquíssimas coisas ficaram de pé, entre elas uma grande mesquita. Era uma sexta-feira, e fomos até lá. Como esse é o dia sagrado dos mulçumanos, todo mundo estava indo rezar.

Àquela altura, por conta do calor e do estado de decomposição, com risco de doenças, os corpos já não estavam mais nem sendo identificados. Fizemos uma matéria sobre essa questão. Jogaram sacos pretos por toda a cidade para as pessoas colocarem os corpos e, depois, os deixarem na rua. Então passavam caminhões - nós fizemos a [sic] imagens deles e depois os seguimos - e levavam os corpos para uma fossa coletiva, como se fossem lixo (MEMÓRIA GLOBO, 2018, p. 367).

Banda Aceh é um cenário de morte, uma cidade cemitério onde os corpos são igualmente respeitados e profanados ao serem comparados a lixo, em que as pessoas morrem ou rezam pelos falecidos. Não é uma cidade interpretada porque o testemunho carece de apontar as causas do tsunami. Uchoa mantém o propósito de contextualização de cenário atingido na cobertura de um desastre ambiental no Japão em 2011. O terremoto de 8,9 graus na escala Richter seguido de tsunami devastou a costa Nordeste do país e provocou um vazamento na usina nuclear de Fukushima.

O nordeste do Japão é uma região mais pobre, onde mora muita gente idosa e aposentada. Eram pessoas que não tinham como correr para outro lugar. Foi muito triste ver aquelas velhinhas abandonadas, com frio e fome, sozinhas. $\mathrm{Na}$ hora que você perde a sua casa, suas roupas, suas fotos, você perde a sua identidade. Numa guerra, mal ou bem, a pessoa que foge ainda pode levar alguma coisa. O tsunami 
entra destruindo tudo. Então, quem realmente sobreviveu, o fez com a roupa do corpo.

Era difícil entrar em hospitais. E, particularmente, acho que tem um limite de quanto sofrimento você consegue ver. $O$ repórter também precisa se preservar, até para que seja capaz de fazer mais coisas. Grandes desgraças são traumáticas. Você entra numa nuvem negra, de desespero coletivo.

Muito das coisas que você vê, não pode mostrar, porque é chocante demais. Acho que os tsunamis têm uma coisa que a guerra não tem. Não é uma destruição no nível de Hiroshima, mas é quase, é uma coisa de terra arrasada. O tsunami leva tudo (MEMÓRIA GLOBO, 2018, p. 374).

A cidade perde a identidade porque as pessoas perdem o ligamento com o lugar de origem e de aconchego. O espaço urbano é tal qual arrasado por uma guerra e por um tsunami, todavia um sobrevivente deste não leva o espaço citadino consigo, deixa todos seus pertences e sua história lá. O fenômeno climático o dividiu entre cartografias dos moradores que devem ficar e dos outros que não podem permanecer $A$ cidade parece resistir diante da situação das vítimas impedidas de fugir para sobreviver. Ela é abandonada pelos nativos ao mesmo tempo no qual abandona seus velhos nos seus próprios espaços, apega-se a seu território mesmo seus sujeitos configurando territorialidades de desagregação. Marcos Aurélio Saquet (2010, p. 97-138) ao enumerar teóricos e paradigmas sobre territorialidade sinaliza que eles sempre a associam com o caráter fragmentário político, econômico, social, ambiental, regional e internacional. O tsunami delimitou os espaços do nativo forçado a ser sedentário, do refugiado e do jornalista descentralizador, mobilizados de modos diferentes por esses aspectos fragmentários. O correspondente internacional trabalha para problematizar e dar conta de todos eles.

A cobertura pareceu seguir essa espécie de higienização fragmentária dos corpos diante das ruínas ao selecionar a angulação dos cenários afetados. A equipe de reportagem vivenciou o trauma de suas fontes informativas. Apesar de precisarem permanecer em meio aos 


\section{tríade}

espaços arrasados, os repórteres optaram por não testemunhar tudo, nem todas as realidades no tempo após o tsunami oferecidas pela cidade semimorta eram passíveis de serem contextualizadas. Se o testemunho é uma mediação jornalística não meramente opinativa, nos termos de Géraldine Muhlmann (2008), a reportagem não destina a sua comunidade nacional a mesma experiência vivida pela presença ocular de seus profissionais; neste caso, Marcos Uchoa forjou dizer o mesmo contexto visto, ou seja, configurou-se enquanto um "embaixador" seletivo, no entanto toda atividade jornalística angula e edita seletivamente. Margarethe Born Steinberger (2005, p. 89) aponta que a lacuna jornalística reflete as decisões de todo jornalista. Uchoa optou por não impactar muito o público do telejornal; ao contrário disso, o visto e o não exibido poderiam oferecer relações contextuais capazes de apontar as causas do acontecimento. "Sua cidade" fragmentada e repartida foi jornalisticamente contextualizada, não interpretada, pois a cobertura não foi aprofundada. As telerreportagens dos tsunamis no continente asiático disponíveis no hotsite do projeto Globo confirmam a indisposição ao jornalismo interpretativo, ou seja, ao tratamento das origens e dos efeitos da tragédia ambiental.

Acompanhando até aqui as representações das cidades devastadas nos testemunhos dos correspondentes internacionais da Rede Globo de Televisão, podemos dizer que compunham uma cobertura paralisante de acordo com Wilson Bueno (2008, p. 170), isolada das causas e da denúncia dos interesses promotores da destruição ecológica, privilegiando sensações em detrimento do aprofundamento da reportagem. Os espaços urbanos jornalisticamente contextualizados não são mediados por meio de relatos das ações humanas agravadoras ou responsáveis pelos desastres ambientais. As cidades são igualmente paralisantes além de paralisadas, cobertas de fantasmagorias, entre elas a letargia sensacionista dos próprios repórteres indispostos a investigar e interpretar os fatos. Wilson 
Gomes (2009, p. 16), ao discutir uma teoria do fato jornalístico, aponta o descrédito da ideia do dado definitivo e independente da subjetividade que o angula; ao contrário, pela descrição factual podem transitar opiniões, desejos, súplicas (p. 32). Neste caso, as narrativas dos repórteres legitimam eles como sujeitos atípicos das cidades, mas também sujeitos geralmente submetidos a mediações impressionistas. Cumprem, de certo modo, com a função política do jornalismo ambiental ao se engajarem com as tragédias pessoais. No entanto falta a eles a predisposição pedagógica de demonstrar as formas de evitar a dimensão da crise ecológica e humana. Todavia, os depoimentos de dois correspondentes no projeto Memória Globo oferecem a possibilidade de um jornalismo interpretativo mesmo diante de problemas ambientais urgentes.

César Tralli exerceu a função de jornalista internacional em Londres por cinco anos (MEMÓRIA GLOBO, 2018, p. 330). Foi enviado especial na cobertura, As mães de Chernobyl, feita dez anos após a explosão da usina nuclear em abril de 1986. Ele visitou a cidade ucraniana de Pripyat e relatou seu testemunho:

Chegando lá, recebemos roupas, botas especiais e uma série de recomendações. Dentre elas, seguir rigorosamente as ordens de quem nos acompanharia. Cada passo seria cronometrado e seguido de perto por aparelhos de medição de radiação. Em alguns pontos da usina, só poderíamos ficar no máximo dois minutos do lado de fora do ônibus militar. $\mathrm{E}$ assim foi nossa aventura por Chernobyl (MEMÓRIA GLOBO, 2018, p. 340).

As palavras revelam uma cidade sitiada pela contaminação nuclear e pela morte. Ela registra em seus espaços, nas ruas, casas e escolas marcas de ausência, dos moradores em fuga, uma cidade fantasma insistente em manter os testemunhos da partida: 


\section{tríade}

O coração apertou ainda mais no pátio. Máscaras de gás se misturavam a carrinhos, soldadinhos de chumbo e bonecas de pano. Dava para imaginar o que tinha ocorrido e os dias seguintes à debandada geral. Muitos meninos e meninas da escolinha e do jardim de infância morreram intoxicados pela fumaça da usina em chamas e por doenças provocadas pela radiação. Uma tragédia que se abateu sobre milhares na Ucrânia e em vários países europeus" (MEMÓRIA GLOBO, 2018, p. 341).

Nas palavras finais do testemunho social e ecológico, percebemos uma Pripyat maior do que sua tragédia particular, pois a nuvem nuclear ali formada espalhou-se por toda a Europa. A cidade "ganhou" o mundo e só foi esquecida apenas pelos seus mortos; ao contrário disso, ela insiste em tê-los consigo. Tralli não oferece indícios em seu depoimento a respeito da cobertura de uma cidade interpretada, todavia o vídeo disponibilizado no hotsite do projeto das Organizações Globo aponta a preocupação com as causas do acidente nuclear: "Máquinas dos anos 60, computadores quebrados, sistema de refrigeração quebrado há duas semanas. Essa sala de controle é idêntica a que operava o reator que foi pelos ares. A diferença é que a tecnologia agora está mais obsoleta". O sucateamento dos equipamentos foi sugerido como o motivo da explosão de um dos reatores. Através do retorno ao trabalho na usina, a cidade parecia tentar sobreviver apesar de um novo perigo anunciado. O discurso da inovação tecnológica, ao contrário, legitima o aspecto pedagógico de propor formas de segurança nuclear inclusive ao governo brasileiro da época que importou ultra-centrifugadoras alemãs para enriquecimento de urânio nos anos 1950.

A correspondente Sônia Bridi também referencia uma cobertura na qual privilegiou as causas dos fatos narrados. Ela produziu as séries especiais Terra, que tempo é esse? Planeta Terra: lotação esgotada e A jornada da vida exibidas no programa Fantástico, nas quais apresentou problemas do planeta em vários continentes e países, entre eles a superpopulação mundial e o aquecimento global. Passou meses no 
escritório da Globo em Londres, transferida em seguida para Nova York. Fundou e assumiu o posto de correspondentes da emissora em Pequim por dois anos até ser transferida ao escritório em Paris. A primeira das séries acima referenciadas virou o livro Diário do clima: efeitos do aquecimento global (2012).

Bridi relata sua experiência na cobertura do superpovoamento na Índia:

Nessa série, também fomos para o Parque Nacional de Sundarbans, no delta indiano do Ganges. Ali, as pessoas vivem em ilhas muito baixas, nas condições mais precárias possíveis para plantar e comer. Só que agora, por causa do aquecimento global, acontecem tempestades, e as ilhas ficam inundadas com a água salgada. Quando isso acontece, a terra fica estéril por três anos, e eles não produzem nada. $\mathrm{Ou}$ as pessoas morrem de fome ou vão para grandes cidades, como Calcutá e Nova Déli, para engrossar favelas. Vimos muita gente gastando o tempo e a energia que restavam construindo barragens de barro ao redor das ilhas para conter as ondas provocadas pelos furacões (MEMÓRIA GLOBO, 2018, p. 317).

A cidade estéril até parece não ser interpretada pela repórter, ela apenas enumera no trecho as consequências socioeconômicas das mudanças climáticas precarizadas pela densidade populacional, mostrando a adaptação dos moradores aos problemas causados pelas alterações antropogênicas do clima. Nas telerreportagens do hotsite, a correspondente destaca as causas do aquecimento. Em Planeta Terra: lotação esgotada, denuncia o problema do desmatamento a partir do ponto de vista social e econômico:

Ruanda tem menos de $1 \%$ dos habitantes da China, mas é tão pequena que pra ter o mesmo número de pessoas por quilômetro quadrado, a China precisaria ter 4 bilhões de habitantes. Com tanta gente concentrada num território pequeno, Ruanda já perdeu quase toda sua floresta. Colina após colina, coberta de plantações. 
Na reportagem da série Terra: que tempo é esse? aponta o problema da poluição mundial: "Nessas pequenas bolhas aprisionadas quando a neve caiu, está o registro da concentração do dióxido de carbono em cada época do planeta [...] a prova de que esse gás provoca o efeito estufa responsável pelo aquecimento". Nos dois casos, assume seu engajamento político e seu propósito pedagógico contra as causas das mudanças climáticas.

O construto interpretativo de Sônia Bridi é análogo às linhas de raciocínio da análise climática apontadas por David Archer e Stefan Rahmstorf (2010, p. 62-63):

First, there are so-called "detection and attribution" studies. This refers to a specific set of statistical techniques which allow us to "detect" climate changes in an observational data set (that means, to distinguish a real change from mere random fluctuations) and to "attribute" these changes to a set of causes $[\ldots]$

Second, there is the overall "balance of evidence" [...] that determines the confidence we have in our understanding of the causes of climate change. This balance of evidence includes the results of the formal "detection and attribution" studies $^{2}$.

A deteç̧ão lida com dados climáticos não aleatórios, a atribuição angula um conjunto de causas e o balanço de evidências aponta as consequências dos fenômenos delimitados nas duas primeiras etapas. Apesar de não cobrir o aquecimento global, César Tralli também faz uso dessas etapas interpretativas em sua cobertura de Chernobyl. Ele e Sônia Bridi são correspondentes internacionais do projeto Memória Globo mais sensíveis à necessidade de compreender a cidade interpretada, ou seja, submetida a um panorama levando em consideração dados de seus espaços, causas e efeitos de problemas destrutivos. Deste modo, as

\footnotetext{
${ }^{2}$ Primeiro, há os conhecidos estudos de "detecção e atribuição". Estes referem-se a um conjunto específico de técnicas estatísticas que nos permite "detectar" mudanças climáticas em dados observados (que significa, distinguir a mudança real das meras flutuações aleatórias) e "atribuir" essas mudanças a um conjunto de causas [...]. Segundo, há o "balanço de evidência" geral [...] que determina a confiança que nós temos no nosso entendimento das causas de mudança climática. Este balanço de evidência inclui os resultados dos estudos formais de "detecção e atribuição" (tradução nossa).
} 
narrativas das cidades são mediadas de modo aprofundado, garantindo testemunhos capazes de apontar soluções necessárias ao restabelecimento dos sentidos de cotidianos e rotinas livres de riscos e catástrofes ambientais.

\section{Considerações finais}

O discurso jornalístico dos correspondentes internacionais é ininterrupto, eles se manifestam independentemente do lugar de fala. Seus testemunhos aparecem nas reportagens e nos relatos fora dos periódicos e dos canais de televisão, nos quais podem ser desagregados das hierarquias editoriais das redações. Eles sempre revelam a mediação de fatos estrangeiros cujos sentidos são compartilhados por determinada comunidade nacional. A cobertura dos correspondentes também não segue de forma rígida a adequação a uma editoria especializada, ao contrário disso propaga a combinatória de discursos políticos, econômicos, sociais, ecológicos. Muitas vezes, os problemas políticos se sobrepõem porque se acumulam e acentuam as tragédias. Uma reportagem de catástrofe serve de experiência a outras; se ela for interpretativa em vez de ser paralisante, apresenta novas perspectivas no tratamento dos fatos e das soluções, no engajamento político e pedagógico contra futuras tragédias anunciadas.

As representações da cidade emergem no discurso ininterrupto, não hierárquico e transitivo dos jornalistas internacionais submetidas a tratamentos contextuais ou interpretativos. O prolongamento das manifestações discursivas reforça o aprofundamento das relações entre dados, causas e consequências dos fatos. A cidade interpretada oferece à cobertura ambiental a convergência entre 0 engajamento do correspondente e o compromisso com a mudança de comportamento dos sujeitos sociais. 
Os testemunhos dos repórteres internacionais a respeito de catástrofes reunidos no projeto Memória Globo mediam a cidade devastada, radioativa, sitiada, deserta, fantasma. A diferença entre eles está na opção pelo jornalismo interpretativo, por meio do qual soluções sinalizadas no tratamento das causas são apontadas para que a cidade resolva suas crises socioeconômicas e ambientais.

O correspondente está em mobilidade constante em diversos países enquanto movimenta sentidos diversos a sua comunidade de origem. Numa cobertura na qual detecta dados, atribui causas e aponta evidências dos efeitos, pode inclusive sugerir soluções a problemas históricos e engessados do seu país. A cidade devastada sofre os efeitos de desastres ambientais provocados pelos humanos em qualquer lugar do mundo. $O$ repórter internacional estará lá a fim de impedir que esse estado de devastação cause a mesma crise humanitária em sua região.

\section{Referências}

AGNEZ, Luciane Fassarella. Correspondente internacional: uma carreira em transição. Curitiba: Appris, 2017.

ARCHER, David; RAHMSTORF, Stefan. The climate crisis: an introductory guide to climate change. Cambridge: Cambridge University Press, 2010.

BELTRÃO, Luiz. Jornalismo interpretativo: filosofia e técnica. Porto Alegre: Sulina, 1976.

BERMAN, Marshall. Tudo que é sólido se desmancha no ar: a aventura da modernidade. São Paulo: Companhia das Letras, 1986.

BUENO, Wilson da Costa. As síndromes do jornalismo ambiental brasileiro. In: MELO, José Marques de (org.). Mídia, ecologia e sociedade. São Paulo: INTERCOM, 2008. p. 161-172.

GOMES, Wilson. Jornalismo, fatos e interesses: ensaios de teoria do jornalismo. Florianópolis: Insular, 2009. 
MARTÍN-BARBERO, Jesús. Ofício de cartógrafo: travessias latinoamericanas da comunicação na cultura. São Paulo: Edições Loyola, 2004.

MEMÓRIA GLOBO (org.). Correspondentes: bastidores, histórias e aventuras de jornalistas brasileiros pelo mundo. Rio de Janeiro: Globo Livros, 2018.

MUHLMANN, Géraldine. A political history of journalism. Cambridge: Polity Press, 2008.

RODRIGUES, Adriano Duarte. Estratégias da comunicação: questão comunicacional e formas da sociabilidade. Lisboa: Editorial Presença, 2001.

RODRIGUES, Adriano Duarte. Delimitação, natureza e funções do discurso midiático. In: PORTO, Sérgio Dayrell (org.). O jornal: da forma ao sentido. 2. ed. Brasília: Editora Universidade de Brasília, 2002. p. 217233.

SAQUET, Marcos Aurélio. Abordagens e concepções de território. 2. ed. São Paulo: Expressão Popular, 2010.

STEINBERGER, Margarethe Born. Discursos geopolíticos da mídia: jornalismo e imaginário internacional na América Latina. São Paulo: EDUC; Fapesp; Cortez, 2005.

UCHOA, Marcos. Terremoto no Japão. Disponível em: memoriaglobo.globo.com. Acesso em: 23 out. 2018. 